University of Nebraska - Lincoln

DigitalCommons@University of Nebraska - Lincoln

Heat Flux Measurements and Modeling of Malodorous

Compounds Above an Anaerobic Swine Lagoon

\author{
Rezaul Mahmood \\ University of Nebraska - Lincoln
}

Follow this and additional works at: https://digitalcommons.unl.edu/natrespapers

Part of the Natural Resources and Conservation Commons, Natural Resources Management and Policy Commons, and the Other Environmental Sciences Commons

Mahmood, Rezaul, "Heat Flux Measurements and Modeling of Malodorous Compounds Above an Anaerobic Swine Lagoon" (2011). Papers in Natural Resources. 1259.

https://digitalcommons.unl.edu/natrespapers/1259

This Article is brought to you for free and open access by the Natural Resources, School of at DigitalCommons@University of Nebraska - Lincoln. It has been accepted for inclusion in Papers in Natural Resources by an authorized administrator of DigitalCommons@University of Nebraska - Lincoln. 


\title{
Heat Flux Measurements and Modeling of Malodorous Compounds above an Anaerobic Swine Lagoon
}

\author{
John H. Loughrin • Arturo I. Quintanar • \\ Nanh C. Lovanh • Rezaul Mahmood
}

Received: 26 April 2010 /Accepted: 10 August 2010/Published online: 1 September 2010

(C) US Government 2010

\begin{abstract}
The concentration of $p$-cresol and $p$-ethylphenol, two malodorants typical of swine waste, were measured at 0.5 and $1.5 \mathrm{~m}$ above a waste treatment lagoon during two separate campaigns encompassing late winter through early spring and late spring through early summer. Concomitant collection of air temperatures, humidities, insolation, and wind speeds, as well as water column temperatures were done so that heat fluxes could be computed using an energy budget method and
\end{abstract}

J. H. Loughrin $(\bowtie) \cdot$ N. C. Lovanh

United States Department of Agriculture,

Agricultural Research Service, Animal Waste Management

Research Unit,

230 Bennett Lane,

Bowling Green, KY 42104, USA

e-mail: john.loughrin@ars.usda.gov

R. Mahmood

Meteorology Program, Western Kentucky University,

1 Big Red Way,

Bowling Green, KY 42101, USA

A. I. Quintanar • R. Mahmood

Department of Geography and Geology,

Western Kentucky University,

College Heights,

Bowling Green, KY 42101, USA

R. Mahmood

Kentucky Climate Center, Western Kentucky University,

College Heights,

Bowling Green, KY 42101, USA
Bowen ratio estimates. The empirical model that was found to correlate best with variations in malodorant concentrations and gradients above the lagoon had the terms describing evaporation from the lagoon surface and net available energy at the lagoon surface. Emissions were found to be much higher during the cool season than the warm season. This was despite much higher evaporation rates during the warm season. This could be explained by much lower lagoon concentrations of the malodorants in the warm season than in the cool season. Results of this work are being used to determine appropriate models to estimate malodorant emissions from lagoons and devise techniques for the abatement of nuisance emissions.

Keywords $p$-cresol $\cdot p$-ethylphenol Evaporation . Heat flux $\cdot$ Lagoon $\cdot$ Malodor

\section{Introduction}

Waste from concentrated animal feeding operations are typically stored and treated in large earthen lagoons prior to land application of wastes (Richard and Hinrichs 2002). In that these lagoons are open to the atmosphere, there is emission of malodorous compounds that can cause complaints by neighbors and may have adverse environmental affects (Schiffman et al. 2001; Lim et al. 2003). 
Of these malodorous compounds, the emission of ammonia has received the most attention both of because of its relative abundance in wastes and due to adverse environmental impacts such as eutrophication of waters (Paerl 1997; Anderson et al. 2002). Relatively high emission rates, and the ability to capture ammonia in acid traps, facilitate its capture and analysis. This has led to numerous calculations of flux rates of ammonia (Aneja et al. 2001; Blunden and Aneja 2008). Emission rates have been calculated using a number of different methods such as enclosed flux chambers (e.g., Aneja et al. 2001; Blunden and Aneja 2008) and various micrometeorological techniques (e.g., Harper and Sharpe 2000; Phillips et al. 2004). Regardless of the method employed, the objective has been to incorporate variables such as $\mathrm{pH}$, wind speed, and temperature into models so that ammonia emissions may be reasonably modeled under varied conditions.

Some of the odorants most strongly characteristic of animal wastes, however, simple phenols and indoles (Spoelstra 1977; Schiffman et al. 2001; Zahn et al. 2001), occur in relatively low levels and do not possess easily ionized functional groups that facilitate their capture. While ammonia may occur in lagoon wastes in concentrations over $1 \mathrm{~g} / \mathrm{L}$, malodorous aromatic compounds more typically occur in the lagoons in nanogram to microgram per liter levels (Merrill and Halverson 2002; Loughrin et al. 2008). Nevertheless, estimates of emission rates of these compounds from waste treatment structures are desirable so that the factors that control their release may be better understood.

In order to gain an appreciation of those factors that influence the release of two of these typical malodorants, $p$-cresol and $p$-ethylphenol, we entrained these compounds on thermal desorption tubes at two heights above a swine waste lagoon with simultaneous collection of meteorological data. These meteorological measurements were used to calculate heat fluxes and net radiation from the lagoon and the values analyzed for correlations with malodorous compound concentrations and gradients.

\section{Experimental Methods}

\subsection{Site Description}

Measurements were performed on an approximately $60 \mathrm{~m}^{2}$ lagoon that served as the primary waste recipient for a farrowing operation of approximately 2,000 sows. Once a week, wastes were flushed from subfloor pits into the lagoon and fresh water was used to partially recharge the pits. There was no pit recharge from the lagoon. Typically, the lagoon was partially pumped down twice yearly, in the fall and spring, for application to crops. In the year of the study, the level of the lagoon was lowered by $10-20 \%$ in April. Agitation was used during pump down to remove as much as of the sludge layer as possible. Volatile collections were performed 11 times from 6 February to 30 March, 2009 and again eight times from 3 June to 25 June, 2009. Lagoon depth was about $2.9 \mathrm{~m}$ during the first collection period and $3 \mathrm{~m}$ during June.

\subsection{Meteorological Measurements}

Measurement of humidity, wind speed, and temperature at 0.5 and $1.5 \mathrm{~m}$ above the lagoon surface were taken by probes mounted on a float constructed from polyvinylchloride (PVC) pipe. The anemometers had an accuracy of $0.1 \mathrm{~ms}^{-1}$ in the range of $5-25 \mathrm{~ms}^{-1}$ and starting speed of $0.32 \mathrm{~ms}^{-1}$ while the temperature/humidity sensor had a range of 3-100\% non-condensing for humidity with an accuracy of $\pm 2 \%$ and a hysteresis of $\pm 1 \%$ and a temperature range of -17 to $70^{\circ} \mathrm{C}$ with an accuracy of $+0.5^{\circ} \mathrm{C}$. The float was anchored to the lagoon by ropes tied to stakes at the side of the lagoon while a data cable led to a solar-powered data logger at the side of the lagoon. The data logger and sensors were all purchased from APRS World, LLC (Winona, MN, USA) and data were recorded in 5-min intervals.

Water temperatures were recorded at the lagoon surface, $0.3,0.6$, and $0.9 \mathrm{~m}$ deep, as well as in the sludge layer by $\mathrm{HOBO}^{\circledR}$ Pro V2 temperature sensors (Onset Computer Corp., Bourne, MA, USA) attached to a PVC pipe float. The sensors had a measurement range of $-40^{\circ} \mathrm{C}$ to $70^{\circ} \mathrm{C}$ with an accuracy of $\pm 0.18^{\circ} \mathrm{C}$ at $25^{\circ} \mathrm{C}$ and a resolution of $0.02^{\circ} \mathrm{C}$. Data were recorded in 5-min intervals.

Meteorological measurements were also recorded $10 \mathrm{~m}$ to the south-west of the lagoon using a 15-channel HOBO weather station. Wind speed, direction, and gust speed were measured by a sensor mounted at a height of $3 \mathrm{~m}$ above the ground. Humidity and air temperature probes were placed in a solar radiation shield at a height of $2 \mathrm{~m}$, and rainfall was measured with a tipping-bucket rain gage mounted at $3 \mathrm{~m}$. Solar radiation at $2 \mathrm{~m}$ high 
was measured with a silicon pyranometer with a spectral range of $300-1,100 \mathrm{~m}$ with a resolution $1.25 \mathrm{Wm}^{-2}$ and an accuracy of $5 \%$. The anemometer had a starting speed of $0.5 \mathrm{~ms}^{-1}$ with an accuracy of $0.5 \mathrm{~ms}^{-1}$ in the range of $17-30 \mathrm{~ms}^{-1}$ while the temperature/humidity sensor had a temperature range of -10 to $75^{\circ} \mathrm{C}$ with an accuracy of $0.2^{\circ} \mathrm{C}$ and a humidity range of $0-100 \%$ non-condensing with an accuracy of $\pm 2.5 \%$ in the range of $10-90 \%$ relative humidity with a hysteresis of $\pm 1 \%$. Again, data was recorded in 5-min intervals.

\subsection{Collection of Malodorous Compounds}

Malodors were collected on thermal desorption tubes containing a $5 \mathrm{~cm}$ long bed of Tenax TA and $2 \mathrm{~cm}$ of Carboxen 569 (Supelco Inc., Bellefonte, PA, USA). Three tubes each were mounted at heights of 0.5 and $1.5 \mathrm{~m}$ on a float constructed of PVC pipe and was connected by tubing to $150 \mathrm{~cm}$ tall flow meters (Bel-Art Products, Pequannock, NJ, USA). The flow meters were connected via a manifold to a 12 VDC diaphragm pump (Gast Manufacturing, Inc., Benton Harbor, MI, USA) and 12 VDC portable power supply (W.W. Grainger, Inc., Chicago, IL, USA). Collections were of $2 \mathrm{~h}$ durations, and during sampling, flow rates were maintained at $250 \mathrm{mLmin}^{-1}$. At the end of sampling, the tubes were placed in air-tight containers and kept cool until analyzed as described below.

\subsection{Gas Chromatography-Mass Spectroscopy}

Gas chromatography-mass spectroscopy was performed on a Gerstel model TDSA thermal desorption system and CIS 3 cooled injector (Gerstel USA Inc., Baltimore, MD, USA) interfaced to a Varian model 3800 gas chromatograph and Saturn 2200 ion trap (Varian Associates, Palo Alto, CA, USA). In the case of air samples, the thermal desorption tubes were desorbed in splitless mode using an initial temperature of $25^{\circ} \mathrm{C}$ with a delay time of $0.25 \mathrm{~min}$ and then heated at $60^{\circ} \mathrm{Cmin}^{-1}$ to $225^{\circ} \mathrm{C}$ with a final time of $3 \mathrm{~min}$. Desorbed volatiles were transferred by a heated transfer line maintained at $240^{\circ} \mathrm{C}$ to a injection liner maintained at $-50^{\circ} \mathrm{C}$ with liquid $\mathrm{CO}_{2}$. After $5 \mathrm{~min}$, compounds were transferred to a $30 \mathrm{~m}$ by $0.25 \mathrm{~mm}$ VF-23MS column (50\% cyanopropylmethylpolysiloxane) with a film thickness of $0.25 \mu \mathrm{m}$ (Varian Inc.) using a 20:1 split and heating the injector at $10^{\circ} \mathrm{Cs}^{-1}$ to $300^{\circ} \mathrm{C}$, a temperature that was held for $3 \mathrm{~min}$. Further GC operating conditions were: column oven temperature maintained at $40^{\circ} \mathrm{C}$ for $2 \mathrm{~min}$ and then programmed at $2^{\circ} \mathrm{Cmin}^{-1}$ to $115^{\circ} \mathrm{C}$ and then at $15^{\circ} \mathrm{Cmin}^{-1}$ to $250^{\circ} \mathrm{C}$ and held for $10 \mathrm{~min}$.

\subsection{Wastewater Quality Analysis}

Wastewater samples were collected using a variation of a technique described previously (Loughrin et al. 2010). Briefly, one pint $(473 \mathrm{~mL})$ glass jars were fitted with lids equipped with 2 two-way ball valves (United States Plastic Corp., Lima, OH, USA). Teflon tape was used on the jar threads to ensure a tight seal and one of the ball valves was connected to a check valve (Smart Products Inc., Morgan Hill, CA, USA). Peristaltic tubing, suspended in the lagoon at depths of 0.3 and $0.9 \mathrm{~m}$, lead from the jars to a portable peristaltic pump (Cole-Palmer, Vernon Hills, IL, USA). Wastewater samples were taken at three locations within the lagoon for each depth.

Wastewater quality and dissolved/suspended gasses were measured as described (Loughrin et al. 2010).

\subsection{Energy Flux Calculations}

In order to understand atmospheric controls over the rate of lagoon emissions, latent heat fluxes were computed using an energy budget method and Bowen ratio estimates (e.g., Ham 1999; Brutsaert 2005; Quintanar et al. 2009). The technique is based on an estimate of the Bowen ratio from measurements of temperature and relative humidity at 0.5 and $1.5 \mathrm{~m}$ above the lagoon surface and at the lagoon surface. Relative humidity was assumed to be $100 \%$ at the lagoon surface. The technique also assumes that the eddy diffusivities for humidity and heat fluxes are the same. Given those measurements of relative and temperature, the Bowen ratio $(B)$ was computed as:

$B=\gamma\left(\frac{T(z 1)-T(z 2)}{e(z 1)-e(z 2)}\right)$

Where $e$ (from relative humidity measurements) and $T$ are vapor pressure estimates and temperature measurements, respectively, taken at two heights $\left(z_{1}\right.$ and $z_{2}$ ) above the lagoon surface and at the lagoon surface. The psychrometric constant $(\gamma)$ is defined as 
$\gamma=C_{p} p /\left(0.622 L_{e}\right)$, where $C_{p}$ is air heat capacity at constant pressure, $p$ is atmospheric pressure and $L_{e}$ is the latent heat of vaporization. In this study, emphasis was placed on evaporation which was directly computed from latent heat fluxes. This was estimated as:

$E=\left(Q_{\mathrm{ne}} L_{e}^{-1}\right)(1+B)^{-1}$

where $Q_{n}$ is the net energy available at the lagoon surface and is defined as:

$Q_{n}=R_{n}-G$

with $R_{n}$ being net solar radiation and $G$ the lagoon heating rate estimated from the measured temperature profile of the water column.

In the absence of direct measurements we followed Brutsaert (2005) to estimate net radiation. To that end, the net radiation further decomposed as:

$R_{n}=R_{S}\left(1-\alpha_{\mathrm{s}}\right)+\varepsilon_{\mathrm{s}} R_{\mathrm{ld}}-R_{\mathrm{lu}}$

where $R_{s}$ is the global short-wave radiation, $\alpha_{\mathrm{s}}$ is the albedo of the water surface, $R_{\mathrm{ld}}$ is the incoming longwave radiation, $\varepsilon_{\mathrm{s}}$ is the emissivity of the lagoon surface and $R_{\mathrm{lu}}$ is the outgoing long-wave radiation from the surface. The latter was estimated as:

$R \mathrm{lu}=\varepsilon s \sigma T_{s}^{4}$

where $\sigma$ is the Boltzmann constant and $T_{S}$ is the absolute temperature of the lagoon surface. The $R_{l d}$ could be expressed as:

$R l d=\varepsilon a c \sigma T_{a}^{4}$

where $\varepsilon_{\mathrm{ac}}$ is the atmospheric emissivity and $T_{a}$ was taken as the atmospheric temperature at $0.5 \mathrm{~m}$. The $\varepsilon_{\text {ac }}$ was represented as:

$\varepsilon_{\mathrm{ac}=} A\left(e\left(z_{2}\right) / T_{a}\right)^{B}$

with $e(z 2)$ the estimated vapor pressure at height $z_{2}$ $(1.5 \mathrm{~m}), B=1 / 7, A=1.16$ for the warm season measurements and $A=1.28$ for the cool season measurements. These values of A provided us with the estimates of atmospheric emissivity and subsequently $R_{n}$ that provided us with good projections of malodorous compound concentration. It needs to be noted that Brutsaert (2005) prescribed $A=1.31$ for entire year and did not provide any seasonal values. However, Crawford and Duchon (1999) provided a methodology for estimating $A$ that accounts for seasonal variations. We have also used the Crawford and Duchon method (Eq. 20) to calculate $A$ and our estimates of seasonal $A$ were comparable (Crawford and Duchon 1999). Side by-side comparison of Brutsaert with Crawford and Duchon provided superior correlations of heat fluxes with malodorous compound concentrations when we used the latter's method.

Data was analyzed in the SAS System for Windows v. 9.1 (SAS Institute Inc., Cary NC, USA 1996).

\section{Results and Discussion}

\subsection{Meteorological Conditions and Wastewater Characteristics}

During the cool season volatile collection period, weather conditions were quite variable as would be expected in February and March given Kentucky's humid subtropical climate (Fig. 1). Winds, for instance, were changeable and predominantly from the south with calms occurring only $2.25 \%$ of the time.

Temperatures and humidity were also variable (Table 1). Air temperature ranged from -3.85 to $22.1^{\circ} \mathrm{C}$, while lagoon surface and sludge temperatures averaged $14.4^{\circ} \mathrm{C}$ and $11.0^{\circ} \mathrm{C}$, respectively. Average humidity was low and ranged from 6.34 to $9.59 \mathrm{gm}^{-3}$. Insolation during the cool season volatile collections averaged $591 \mathrm{Wm}^{-2}$.

During the warm season collections, winds were calmer and predominately from the southwest (Fig. 1). In the case of both cool and warm season collections, wind readings from the swine waste lagoon weather station were in reasonable agreement with those obtained from a nearby Kentucky Mesonet weather station (Logan County, Kentucky Mesonet, 36.854 N, $86.92 \mathrm{~W}$, http://www.kymesonet.org).

In the warm season, air, lagoon surface and sludge temperature averaged $28.3^{\circ} \mathrm{C}, 29.7^{\circ} \mathrm{C}$, and $27.8^{\circ} \mathrm{C}$, respectively (Table 1 ). As expected, humidity was much higher in the warm season, averaging $23.8 \mathrm{gm}^{-3}$. In the case of both cool and warm season collection campaigns, no condensing conditions occurred, averaging $55.7 \%$ and $66.7 \%$ relative humidity during the cool and warm seasons, respectively. During one warm season collection period, however, relative humidity reached as high as $97.8 \%$ (corresponding to $27.4 \mathrm{gm}^{-3}$ water vapor). At no time was any condensation observed in the Tenax tubes, however. Average 
Fig. 1 Wind rose plots for wind speed and direction during volatile collections

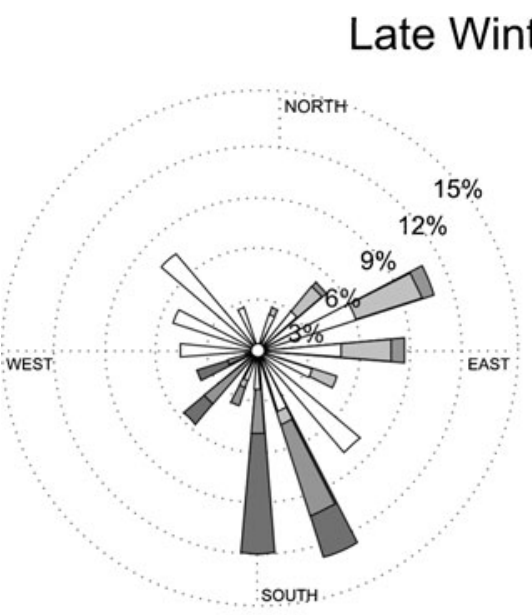

Calms 2.25\%

Waste Lagoon

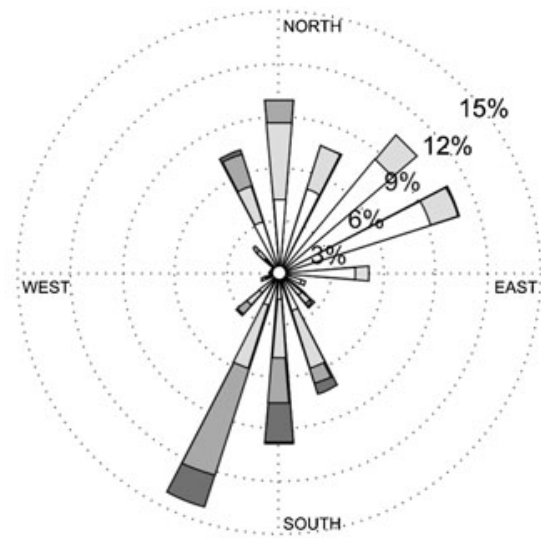

Calms $5.78 \%$ KY Mesonet

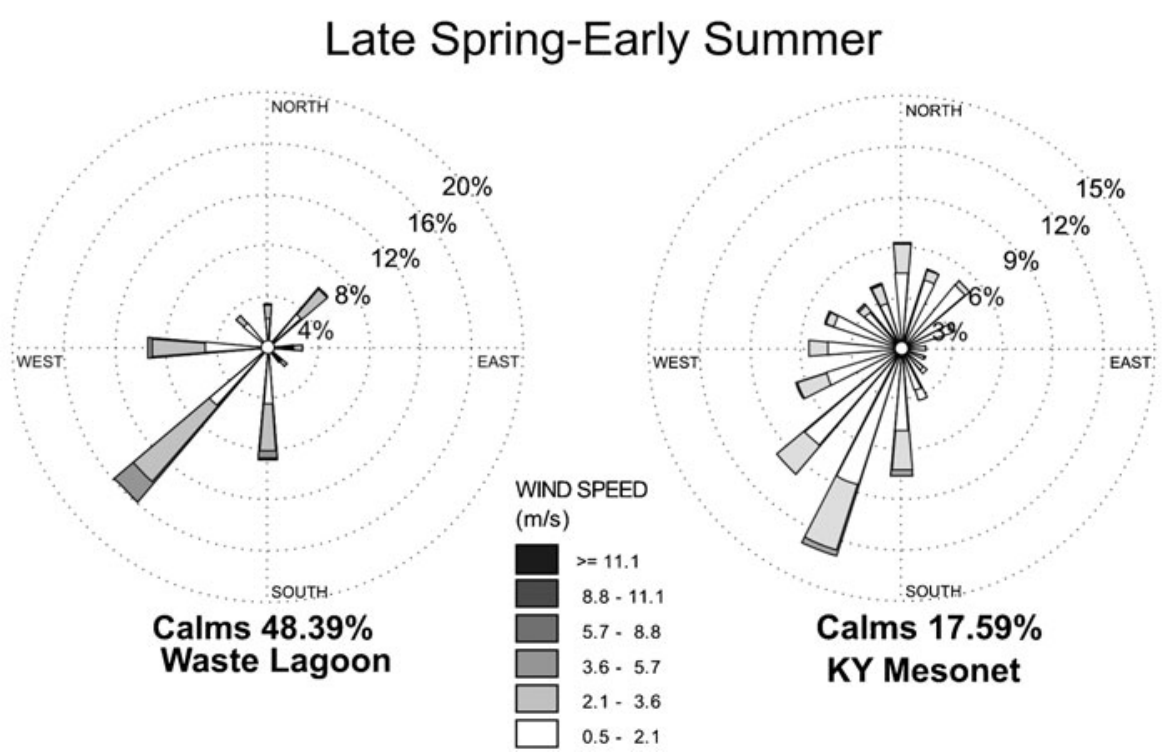

insolation was slightly less than during the cool season collections at $572 \mathrm{Wm}^{-2}$.

Although there were marked differences in wastewater quality between the cool and warm season collection campaigns, these were not in general as pronounced as was the case in meteorological conditions (Fig. 2). Chemical oxygen demand and ammonia declined by approximately $62 \%$ and $35 \%$, respectively, while organic carbon and nitrogen content declined by about $18 \%$ and $11 \%$. Total suspended solids, on the other hand, increased by about $11 \%$ in the warm season. $\mathrm{pH}$ averaged 7.65 in the cool season and 7.87 in the warm season.

The wastewater concentrations of malodorants were dramatically lower during the warm season than they were during the cool season, however. Para-cresol and p-ethylphenol averaged 29,600 and $3,700 \mu \mathrm{gL}^{-1}$, respectively, in the cooler months and 1,460 and $331 \mu \mathrm{gL}^{-1}$ in the warm season. Thus, there was markedly less malodorants available for volatilization during the warmer season. For instance, air concentrations of $p$-cresol at $0.5 \mathrm{~m}$ above the lagoon surface averaged 26,100 and $1,130 \mathrm{ngm}^{-3}$ during the cool season and warm season collections, respectively. That declines in the concentrations of malodorous compounds in waste lagoons occur during the warm season is well known, and are most commonly thought to be due to a combination of factors including microbial catabolism (Gu and Berry 1991; Do et al. 2003) 
Table 1 Descriptive statistics (mean and range) of meteorological conditions during volatile collections

\begin{tabular}{lll}
\hline $\begin{array}{l}\text { Factor } \\
\text { Meteorological } \\
\text { conditions }\end{array}$ & Winter-early spring & Late spring-summer \\
\hline $\begin{array}{l}\text { Air } \\
\text { temperature, } \\
\left({ }^{\circ} \mathrm{C}\right)\end{array}$ & $12.4(-3.9$ to 22.1$)$ & 28.3 (24.4 to 31.9$)$ \\
$\begin{array}{l}\text { Lagoon } \\
\text { surface } \\
\text { temperature, } \\
\left({ }^{\circ} \mathrm{C}\right)\end{array}$ & $14.4(3.8$ to 31.6$)$ & 29.7 (27.3 to 35.7$)$ \\
$\begin{array}{l}\text { Sludge } \\
\text { temperature, } \\
\left({ }^{\circ} \mathrm{C}\right)\end{array}$ & $11.0(3.7$ to 15.7$)$ & $27.8(25.1$ to 30.9$)$ \\
$\begin{array}{l}\text { Insolation } \\
\left(\mathrm{Wm}^{-2}\right)\end{array}$ & $591.0(148.1$ to 964.4$)$ & $572.0(75.6$ to 1066.4$)$ \\
$\begin{array}{l}\text { Humidity } \\
\left(\mathrm{gm}^{-3}\right)\end{array}$ & $6.34(1.53$ to 9.59$)$ & $23.8(9.0$ to 26.7$)$ \\
$\begin{array}{l}\text { Evaporation } \\
\left(\mathrm{mmm}^{-2} \mathrm{~h}^{-1}\right)\end{array}$ & $0.33(-0.24$ to 1.89$)$ & $5.28(-0.51$ to 8.48$)$ \\
$\begin{array}{l}\text { Net Radiation } \\
\left(\mathrm{Wm}^{-2} \mathrm{~h}^{-1}\right)\end{array}$ & $173(-111$ to 677$)$ & $141(-17.5$ to 237$)$ \\
\hline
\end{tabular}

and losses due to evaporation as the lagoons warm during the spring (Pfast and Fulhage 2000).

\subsection{Lagoon Energy Budget and Malodorant Emissions}

The model of choice was based on obtaining the largest correlation, as determined using PROC STEPWISE in SAS, between the concentration of the malodorants at $0.5 \mathrm{~m}$ above the lagoon surface as well as the gradient in their concentrations between $0.5 \mathrm{~m}$ and $1.5 \mathrm{~m}$ and derived meteorological variables such as latent and sensible heat fluxes, lagoon heating $(G)$ and net radiation $\left(R_{\mathrm{n}}\right)$. The model that was most successful in explaining the observed variations in absolute concentrations and their vertical gradients was the model that included net radiation and evaporation jointly (Table 2).

While correlations with evaporation rates alone were rather high, it was found that this term on its own did not adequately explain variations in malodor concentrations and gradients. Thus, the $R_{\mathrm{n}}$ term was required. The coefficients for the regressions were:

$$
\begin{aligned}
& p- \text { cresol : Concentration } \\
& 0.5 m \\
&=-350+(-3,080 \times \text { evaporation }) \\
&+\left(60.6 \times R_{n}\right)
\end{aligned}
$$

$$
\begin{aligned}
& \Delta \text { Concentration }_{0.5 m-1.5 m} \\
& \begin{aligned}
= & -1,890+(-1,904 \times \text { evaporation }) \\
& +\left(40.9 \times R_{n}\right)
\end{aligned}
\end{aligned}
$$

$$
\begin{gathered}
p \text { - ethylphenol : } \text { Concentration }_{0.5 m} \\
=44.7+(-376 \times \text { evaporation }) \\
+\left(7.44 \times R_{n}\right)
\end{gathered}
$$

Fig. 2 Lagoon wastewater characteristics during late winter-early spring and late spring-early summer odor collection campaigns

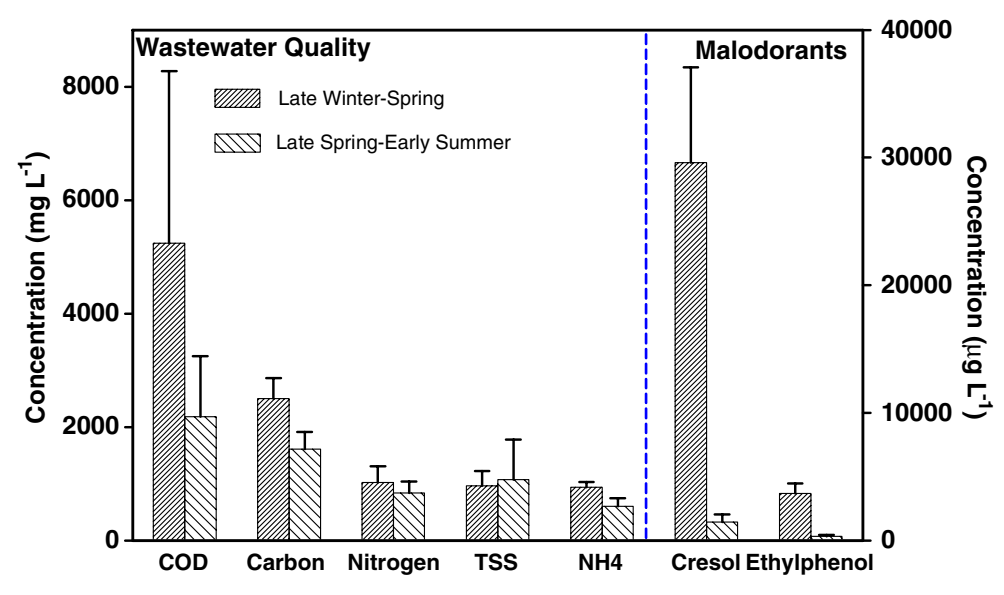


Table 2 Results of statistical analyses for the determination of predictor variables for malodorant concentrations and gradients above the lagoon surface

\begin{tabular}{|c|c|c|c|c|c|}
\hline & \multirow[b]{2}{*}{ Source } & \multicolumn{2}{|c|}{$\begin{array}{l}\text { Compound Concentration at } 0.5 \mathrm{~m} \\
\text { height }\end{array}$} & \multicolumn{2}{|c|}{$\Delta$ Concentration $0.5-1.5 \mathrm{~m}$} \\
\hline & & $\operatorname{Pr}>F$ & $r^{2}$ & $\operatorname{Pr}>F$ & $r^{2}$ \\
\hline \multirow[t]{3}{*}{$p$-Cresol } & Model & $<0.0001$ & 0.7369 & $<0.0001$ & 0.7538 \\
\hline & Evaporation & 0.0007 & 0.4979 & 0.0012 & 0.4696 \\
\hline & $R_{\mathrm{n}}$ & 0.0015 & 0.2390 & 0.0006 & 0.2842 \\
\hline \multirow[t]{3}{*}{$p$-Ethylphenol } & Model & $<0.0001$ & 0.7184 & 0.0002 & 0.6606 \\
\hline & Evaporation & 0.0010 & 0.4834 & 0.0032 & 0.4081 \\
\hline & $R_{\mathrm{n}}$ & 0.0021 & 0.2350 & 0.0033 & 0.2525 \\
\hline
\end{tabular}

$\Delta$ Concentration $_{0.5 m-1.5 m}$

$$
\begin{aligned}
= & -238+(-239 \times \text { evaporation }) \\
& +\left(5.18 \times R_{n}\right)
\end{aligned}
$$

where $\Delta$ Concentration C. $_{0 m-1.5 m}$ is the difference in malodorant concentration at 0.5 and $1.5 \mathrm{~m}$ above the lagoon surface.

These regressions explained about $74 \%$ of the variations in $p$-cresol concentration and $72 \%$ of the variations in $p$-ethylphenol concentration above the lagoon surface, respectively, and were similarly successful in describing the variations in the malodor concentration gradients. As noted, the concentrations of $p$-cresol and $p$-ethylphenol in the lagoon wastewater were much lower in the warm season than during the cool season and in consequence the concentrations of malodorants in the air above the lagoon were also much lower (Fig. 3). Therefore, since the model included both cool season collections when evapora-

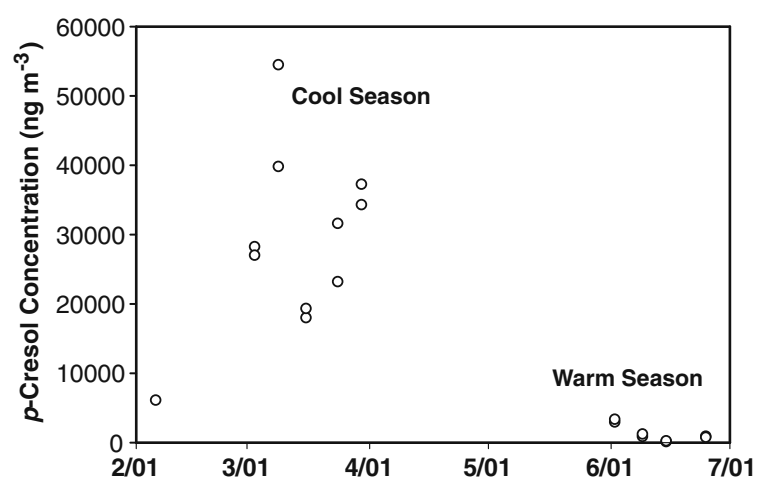

Fig. 3 Para-Cresol concentrations $0.5 \mathrm{~m}$ above the lagoon surface tion rates on average were low, and warm season collections, when evaporation rates were relatively high, the evaporation terms have negative coefficients. It must be noted, nevertheless, when the cool season and warm season collection campaigns were
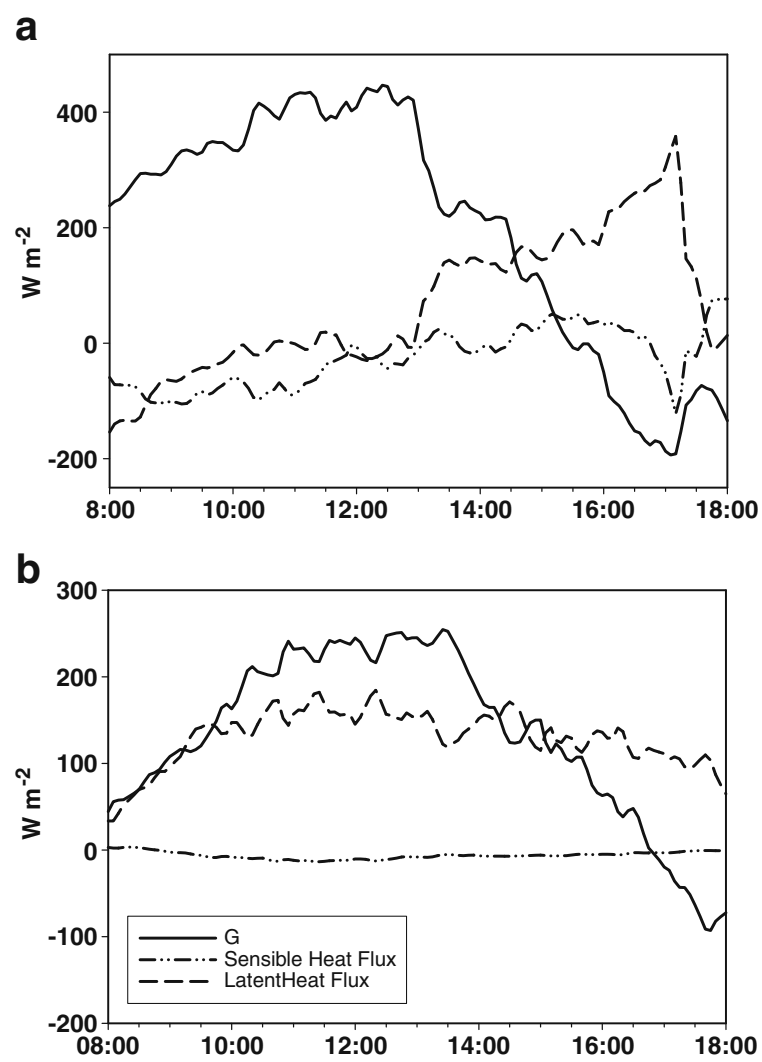

Fig. 4 Average daytime lagoon heating, latent and sensible heat fluxes during days on which samples were taken in the cool season (a) and warm season (b) odor collection campaigns 
considered separately, the relationship of both evaporation and $R_{\mathrm{n}}$ to the variations in malodorant concentrations and gradients were positive.

As exemplified by the case of $p$-cresol, malodorant concentrations were much more sensitive to changes in net available lagoon energy than to changes in evaporation rates. As noted, the relationship between evaporation and malodorant concentrations was negative. Changes in evaporation rates did not affect malodorant emissions as profoundly as did changes in $R_{\mathrm{n}}$, however. For instance, when the evaporation rate was held equal to zero, changes in $R_{\mathrm{n}}$ resulted in $p$-cresol concentrations at $0.5 \mathrm{~m}$ above the lagoon surface from 0 to over $30,000 \mathrm{ngm}^{-3}$. When the evaporation rate was held constant at $6 \mathrm{mmh}^{-1}$, $p$-cresol concentrations at that same height ranged from approximately 2,000 to over $15,000 \mathrm{ngm}^{-3}$.

While lagoon heating rates during midday, when the majority of volatile collections were done, were comparable during the cool season and warm season collection campaigns (Fig. 4), latent heat fluxes were much lower during the cool season. In fact, appreciable latent heat fluxes were not noted during days upon which volatile collections were performed until late in the afternoon. Given our findings, the greatest emission of malodorants from the lagoon should occur during this period during the cool season whereas emissions throughout the day are likely to be more constant during the warm season. It should also be noted that appreciable sensible heat fluxes were not detected during either season. This behavior has also been reported in studies in which water is not limited such as lakes and shallow lagoons (Rodríguez-Rodríguez and Moreno-Ostos 2006; Tanny et al. 2008).

\subsection{Discussion of Findings and Conclusion}

In conclusion, by the collection and measurement of malodorous compounds at two heights above the surface of a swine waste lagoon along with concomitant measurement of environmental parameters such as wind speed and temperature at the same heights, we were able to investigate the relationship of the emission of these compounds to the energy budget of the lagoon. We found that the emission $p$-cresol and $p$-ethylphenol from a swine waste lagoon are dependent on evaporation and the net available energy at the lagoon surface.
The results from heat flux calculations have been used in numerous instances to estimate fluxes of volatile compounds from numerous sources under varied situations. Just a few examples include ammonia emissions from waste lagoons (Phillips et al. 2004), terpenes, and other volatile emissions from forests (Ieda et al. 2006) and the volatilization of pesticides from bare fields and crops (Parmele et al. 1972). Results of the present work are being used as a means of selecting models so as to be able to estimate fluxes of malodorants from waste lagoons and thereby develop reasoned approaches to the mitigation of these nuisance compounds. For instance, shelterbelts of trees or shrubs have been proposed as a means of reducing emissions from animal rearing facilities (Tyndall and Grala 2006, 2009). While these shelterbelts are normally seen as a means of controlling emissions by reducing wind speeds, our results indicate that in the case of waste lagoons at least, shelterbelts might be more effective if placed so as to reduce exposure to the sun and hence lagoon heating.

Acknowledgments We thank Joe St. Claire and Marty Haley (USDA-ARS) for technical assistance. We thank Mike Grogan and Andrew Quilligan of the Kentucky Climate Center for their technical assistance. We also thank Xingang Fan and Ronnie Leeper for their comments and suggestions related to preparation of the manuscript. This research was part of United States Department of Agriculture-Agricultural Research Service National Program 206: Manure and Byproduct Utilization. Additional funding was obtained through a United States Department of Agriculture grant \#58-6445-6068. This research also benefited from National Science Foundation-EPSCoR funding. Mention of a trademark or product anywhere in this article is to describe experimental procedures and does not constitute a guarantee or warranty of the product by the USDA and does not imply its approval to the exclusion of other products or vendors that may also be suitable.

\section{References}

Anderson, D. M., Gilbert, P., \& Burkholder, J. M. (2002). Harmful algal blooms and eutrophication nutrient sources, composition, and consequences. Estuaries, 25 (4b), 704-726.

Aneja, V., Braham, P., Malik, B., Tong, Q., Kang, D., \& Overton, J. (2001). Measurement and modelling of ammonia emissions at waste treatment lagoon-atmospheric interface. Water, Air, and Soil Pollution: Focus, 1(5-6), $177-188$.

Blunden, J., \& Aneja, V.P. (2008). Characterizing ammonia and hydrogen sulfide emissions from a swine waste treatment 
lagoon in North Carolina. Atmospheric Environment, 42 (14), 3277-3290.

Brutsaert, W. (2005). Hydrology: An introduction. Cambridge: Cambridge University Press.

Crawford, T. M., \& Duchon, C. E. (1999). An improved parameterization for estimating effective atmospheric emissivity for use in calculating daytime downwelling longwave radiation. Journal of Applied Meteorology, 38 (4), 474-480.

Do, Y. S., Schmidt, T. M., Zahn, J. A., Boyd, E. S., de la Mora, A., \& DiSpirito, A. A. (2003). Role of Rhodobacter sp. strain PS9, a purple nonsulfur photosynthetic bacterium isolated from an anaerobic swine waste lagoon, in odor remediation. Applied and Environmental Microbiology, 69 (3), 1710-1720.

Gu, J.-D., \& Berry, D. F. (1991). Degradation of substituted indoles by an indole-degrading methanogenic consortium. Applied and Environmental Microbiology, 57(9), 26222627.

Ham, J. M. (1999). Estimating evaporation and seepage losses from lagoons used to contain animal waste. Transactions of the American Society of Agricultural Engineers, 42(5), 1303-1312.

Harper, L. A., \& Sharpe, R. R. (2000). Gaseous nitrogen emissions from anaerobic swine lagoons: Ammonia, nitrous oxide, and dinitrogen gas. Journal of Environmental Quality, 29(4), 1356-1365.

Ieda, T., Kitamori, Y., Mochida, M., Hirata, R., Hirano, T., Inukai, K., et al. (2006). Diurnal variations and vertical gradients of biogenic volatile and semi-volatile organic compounds at the Tomakomai larch forest station in Japan. Tellus B, 58(3), 177-186.

Kentucky Mesonet. http://www.kymesonet.org. Accessed 01 September 2009.

Lim, T.-T., Heber, A. J., Ni, J. Q., Sutton, A. L., \& Shao, P. (2003). Odor and gas release from anaerobic treatment lagoons for swine manure. Journal of Environmental Quality, 32(2), 406-416.

Loughrin, J. H., Lovanh, N., \& Mahmood, R. (2008). Equilibrium sampling used to monitor malodors in a swine waste lagoon. Journal of Environmental Quality, 37(1), 1-5.

Loughrin, J. H., Bolster, C., Lovanh, N., \& Sistani, K. R. (2010). A device for the collection of water at well defined depth. Applied Engineering in Agriculture, 26 (in press).

Merrill, L., \& Halverson, L. J. (2002). Seasonal variation in microbial communities and organic malodor indicator compound concentrations in various types of swine manure storage systems. Journal of Environmental Quality, 31(6), 2074-2085.
Paerl, H. W. (1997). Coastal eutrophication and harmful algal blooms: importance of atmospheric deposition and groundwater as "new" nitrogen and other nutrient sources. Limnology and Oceanography, 42(2), 1154-1165.

Parmele, H., Lemon, E. R., \& Taylor, A. W. (1972). Micrometeorological measurement of pesticide vapor flux from bare soil and corn under field conditions. Water, Air, \& Soil Pollution, 1(4), 3469-3480.

Pfast, D. L. \& Fulhage, C. D. (2000). Anaerobic lagoons for storage/treatment of livestock manure. University of Missouri Extension Publication EQ387.

Phillips, S. B., Arya, S. P., \& Aneja, V. P. (2004). Ammonia flux and dry deposition velocity from near-surface concentration gradient measurements over a grass surface in North Carolina. Atmospheric Environment, 38(21), 3469-3480.

Quintanar, A. I., Mahmood, R., Loughrin, J. H., Lovanh, N., \& Motley, M. V. (2009). A system for estimating Bowen ratio and evaporation from waste lagoons. Applied Engineering in Agriculture, 25(6), 923-932.

Richard, T. L., \& Hinrichs, C. C. (2002). Management and maintenance of earthen manure structures: implications and opportunities for water quality protection. Applied Engineering in Agriculture, 18(6), 727-734.

Rodríguez-Rodríguez, M., \& Moreno-Ostos, E. (2006). Heat budget, energy storage and hydrological regime in a coastal lagoon. Limnologica, 36(4), 217-227.

SAS Institute (1996). SAS system for windows. Version 9.1. Cary: SAS Inst.

Schiffman, S. S., Bennett, J. L., \& Raymer, J. H. (2001). Quantification of odors and odorants from swine operations in North Carolina. Agricultural and Forest Meteorology, 108 (3), 213-240.

Spoelstra, S. K. (1977). Simple phenols and indoles in anaerobically stored piggery wastes. Journal of the Science of Food and Agriculture, 28(5), 415-423.

Tanny, J., Cohen, S., Assouline, S., Lange, F., Grava, A., Berger, D., et al. (2008). Evaporation from a small water reservoir: Direct measurements and estimates. Journal of Hydrology, 351(2), 218-229.

Tyndall, J. C., \& Grala, R. K. (2006). Mitigating swine odor with strategically designed shelterbelt systems: A review. Agroforestry Systems, 69(1), 45-65.

Tyndall, J. C., \& Grala, R. K. (2009). Financial feasibility of using shelterbelts for swine odor mitigation. Agroforestry Systems, 76(1), 237-250.

Zahn, J. A., DiSpirito, A. A., Do, Y. S., Brooks, B. E., Cooper, E. E., \& Hatfield, J. L. (2001). Correlation of human olfactory responses to airborne concentrations of malodorous volatile organic compounds emitted from swine effluent. Journal of Environmental Quality, 30(2), 624-634. 